\title{
Heat Transfer Analysis of a Diesel Engine Head
}

\author{
M. Diviš, R. Tichánek, M. Španiel
}

This paper documents the research carried out at the Josef Božek Research Center of Engine and Automotive Engineering dealing with extended numerical stress/deformation analyses of engines parts loaded by heat and mechanical forces. It contains a detailed description of a C/28 series diesel engine head FE model and a discussion of heat transfer analysis tunning and results. The head model consisting of several parts allows a description of contact interaction in both thermal and mechanical analysis.

Keywords: heat transfer analysis, FEM, internal-combustion engine.

\section{Introduction}

The peak temperatures of burning gases inside the cylinder of diesel engines are of the order of $2500 \mathrm{~K}$. To prevent overheating, the maximum temperatures of the metal surfaces enclosing the combustion chamber are limited to much lower values and, therefore, cooling must be provided for the cylinder, cylinder head and piston. The substantial heat fluxes and temperature nonuniformities arising from these conditions lead to thermal stresses, which further escalate the otherwise significant mechanical loading from combustion pressures. The design must take into account all these considerations to ensure trouble-free operation of engines, which, especially in the case of parts of complex design, requires an extended analysis based on detailed information of all the processes involved.

The cylinder head is one of the most complicated parts of an internal combustion engine. It is directly exposed to high combustion pressures and temperatures. In addition, it needs to house intake and exhaust valve ports, the fuel injector and complex cooling passages. Compliance with all these requirements leads to many compromises in design. As a result, cylinder heads tend to fail in operation (distortions, fatigue cracking) due to overheating in regions of limited cooling.

In this study, we have put emphasis on the problematic regions around the valve seats and narrow bridges between valves. These regions experience especially severe thermal loading, as they receive heat not only from in-cylinder burning gases during the combustion period but also from burned gases flowing through the exhaust valve and along the exhaust-port walls during the exhaust. Although the temperatures of exhaust gases are significantly lower than peak in-cylinder temperatures, rapid movement of flowing gases there promotes the heat transfer to the walls. Most of the heat accumulated in the valve is rejected through the contact surface of the valve seat. Therefore, any deformations of these parts accompanied by improper contact and occurrence of leakage on the conical valve contact face dramatically increase the thermal loading of the valves and, therefore, may lead to their destruction.

A detailed FE heat-transfer analysis can provide valuable information on the temperature distribution in the overall assembly of the cylinder head, especially in those regions where experimental data is almost impossible to gather. Moreover, this is the first logical stage of cylinder head strength analysis.
In the next step, the temperature and mechanical stresses have to be analysed using temperature field and pressure (and other mechanical loads, e.g., belt pre-stress). The resulting displacement/stress fields may be utilised for evaluation of operational conditions, e.g., contact pressure between valves and valve port uniformity, as well as strength and failure resistance of the assembly. Such information contributes to a detailed understanding of the thermal and mechanical processes in the cylinder-head assembly under engine operation, which is a prerequisite for further optimisation of engine design.

\section{Cylinder-head assembly}

In the present study, the cylinder head of a big turbocharged direct-injection diesel engine is analysed. The engine is used in power generation units. The basic parameters of the engine are: bore $275 \mathrm{~mm}$, stroke $330 \mathrm{~mm}$, maximum brake mean effective pressure $1.96 \mathrm{MPa}$, nominal speed $750 \mathrm{rpm}$.

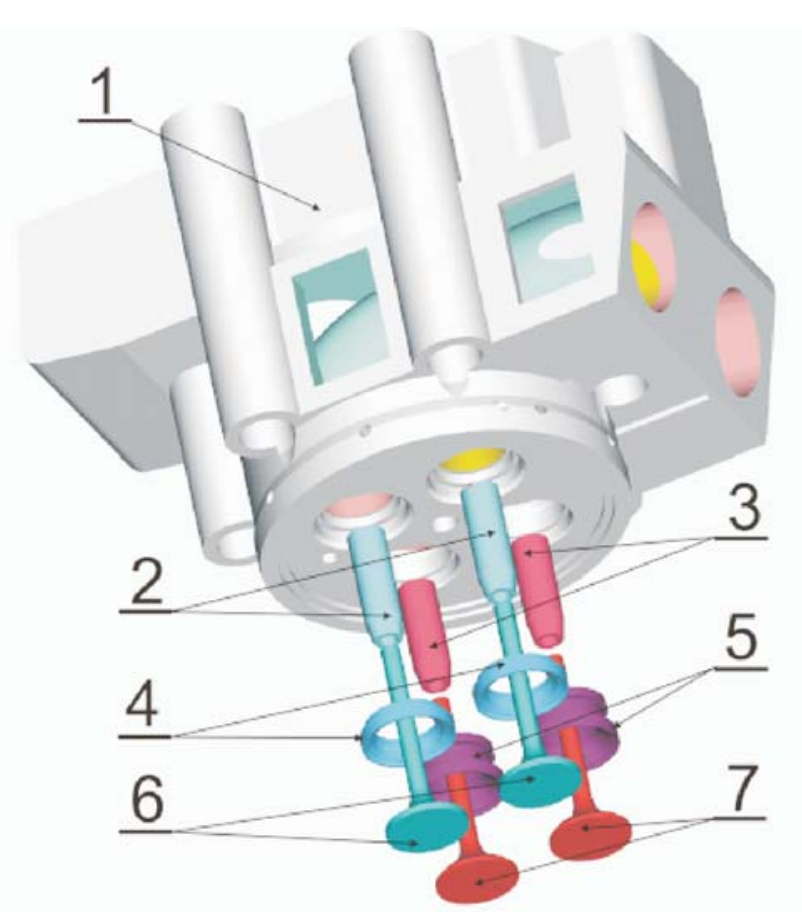

Fig. 1: Cylinder head assembly 


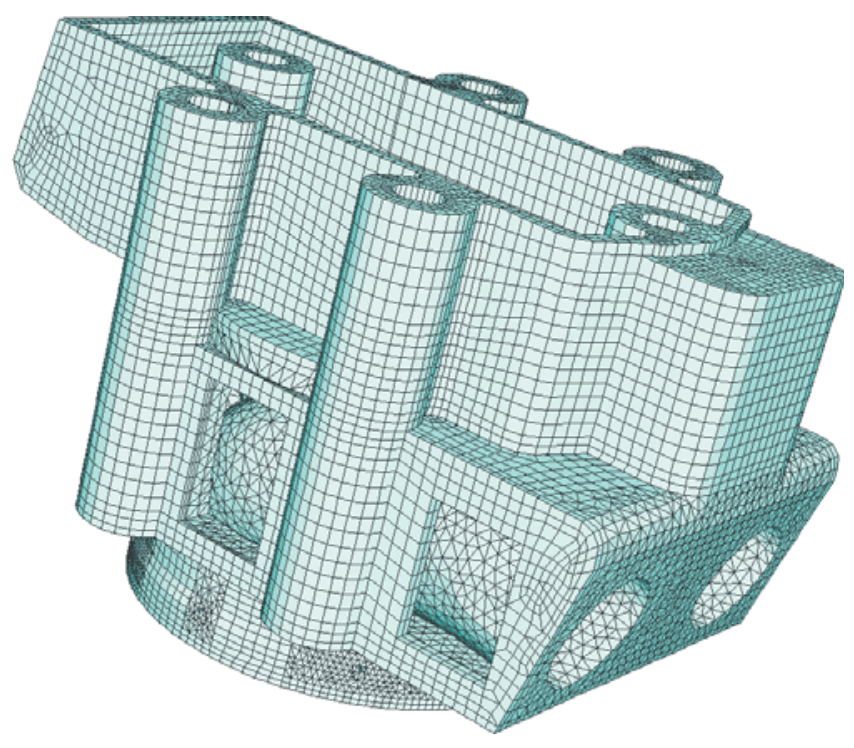

Fig. 2: Mesh geometry

The cylinder head (Fig. 1, link 1) is made of cast iron. It contains two intake valves (Fig. 1, link 6) and two exhaust valves (Fig. 1, link 7) made of forged alloy steel. The valve guides $(2,3)$ as well as the valve seats $(4,5)$ are pressed into the head. The exhaust-valve seats are cooled by cooling water flowing through the annular cavities around the seats. The fuel injector is situated inside the axis of the cylinder. The bottom face of the cylinder head, directly exposed to the in-cylinder gases, is cooled by special bores, which, however, represent a further complication in the design of this mechanically highly loaded region of the cylinder head.

\section{The FE model}

Our FE model includes all components mentioned above, see also Table 1 . The real design of the cylinder head was slightly modified in details to enable manageable meshing. The model of the cylinder head block was created using PRO/ENGINEER 3D product development software and was imported as a CAD model, unlike the models of other compo- nents (valves, seats, valve guides and fuel-injector), which were developed directly in ABAQUS CAE. Some parts of the valves and fuel-injector were considerably simplified or completely left out, as they were considered to have a negligible influence on the results. More information on the mesh geometry and statistics are provided in Fig. 2 and Table 1.

\section{Interactions and boundary conditions}

Although the thermal loadings of engine parts vary considerably in time due to the cyclical nature of engine operation, the computations were performed assuming steady-state heat fluxes evaluated on the basis of time-averaged values. Taking into account the speed of the periodical changes and the thermal inertia of the components of the cylinder head, the temperature variations are damped out within a small distance from the wall surface $(\sim 1 \mathrm{~mm})$, and this simplification is therefore acceptable.

The thermal contact interactions between individual parts of the cylinder head assembly are described by heat flux $q_{A B}$ from the solid face $A$ to $B$, which is related to the difference of their surface temperatures $T_{A}, T_{B}$ according to

$$
\dot{q}_{A B}=k\left(T_{B}-T_{A}\right),
$$

where $k$ is the contact heat-transfer coefficient. The values of the coefficient used in the present analysis are summarised in Table 2. They follow the values reported in [3].

The boundary conditions of surfaces contacted by flowing gases are described as a steady-flow convective heat-transfer problem, where the heat flux $q$ transferred from a solid surface at temperature $T$ to a fluid at bulk temperature $T_{0}$ is determined from the relation,

$$
\dot{q}=h\left(T-T_{0}\right) \text {, }
$$

where $h$ denotes the heat-transfer coefficient. This depends on the flow, the properties of the fluid and the geometry of the surfaces. Functional forms of these relationships are usually developed with the aid of dimensional analysis. In the present study, the values of gas-side heat-transfer coefficients and bulk gas temperatures (i.e., for in-cylinder surfaces and intake and exhaust port walls) were obtained from a de-

\begin{tabular}{|c|c|c|c|c|c|c|}
\hline \multirow[t]{3}{*}{ Part } & \multirow[t]{3}{*}{ Nodes } & \multicolumn{5}{|c|}{ Elements } \\
\hline & & DC3D8 & DC3D6 & DC3D4 & DS4 & DC1D2 \\
\hline & & brick & prism & tetrahedron & shell & link \\
\hline Cylinder head & 67282 & 21636 & 174 & 149162 & - & - \\
\hline Inlet valve seat $(2 \times)$ & 4800 & 3360 & - & - & - & - \\
\hline Exhaust valve seat $(2 \times)$ & 4640 & 2880 & - & - & - & - \\
\hline Inlet valve $(2 \times)$ & 5038 & 3448 & 56 & 2205 & - & - \\
\hline Exhaust valve $(2 \times)$ & 6112 & 4008 & 56 & 2048 & - & - \\
\hline Inlet valve guide & 1560 & 1000 & - & - & - & - \\
\hline Exhaust valve guide & 1716 & 1100 & - & - & - & - \\
\hline Fuel injector & 6644 & 4412 & - & 5171 & 32 & 2 \\
\hline
\end{tabular}

Table 1: Mesh statistics of individual parts (elements signed according to their ABAQUS names) 


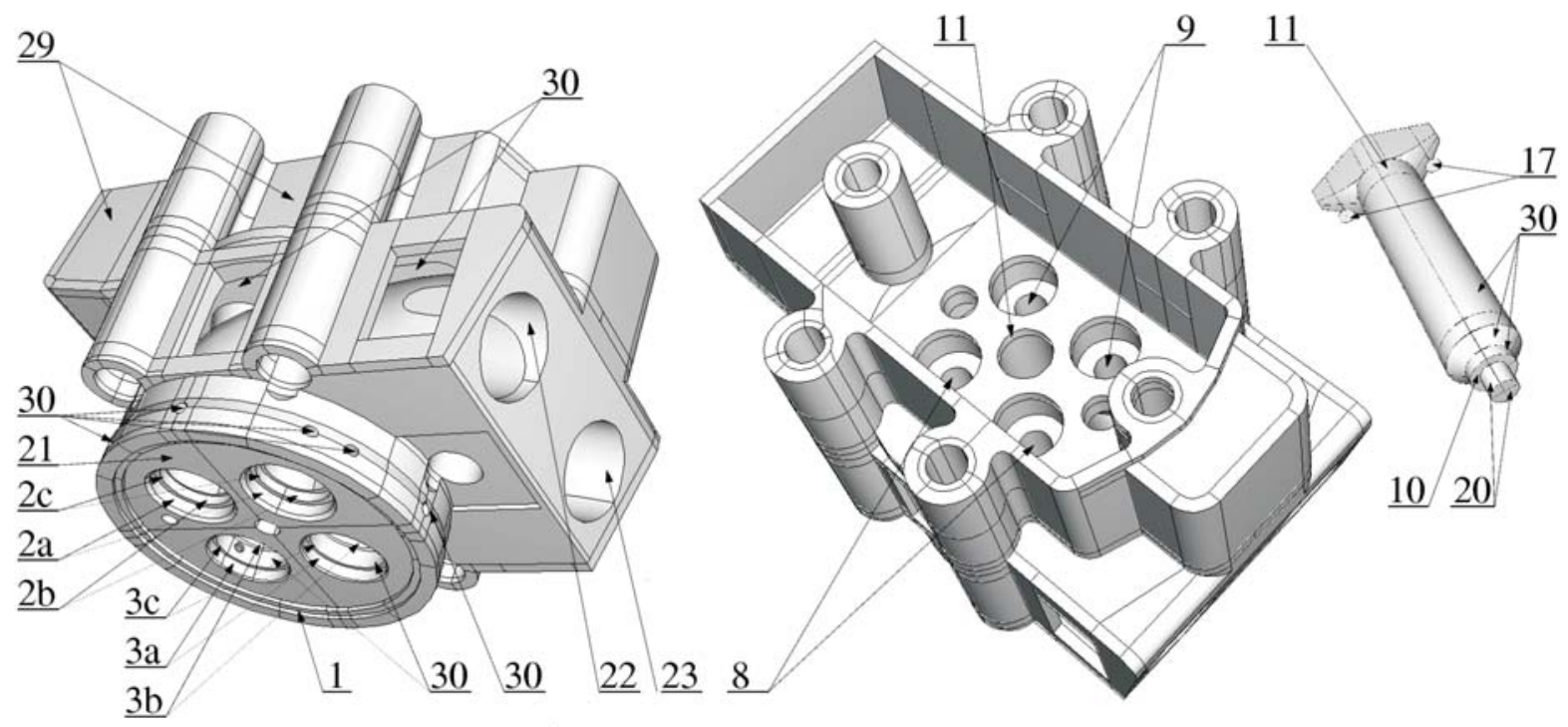

Fig. 3: Interactions and boundary conditions on a cylinder-head block

Table 2: Interactions between single parts considered in FE model (acting surfaces linked in Fig. 3 and 4)

\begin{tabular}{|l|c|c|}
\hline Interaction description & Link & Contact heat transfer coefficient $k\left[\mathrm{~W} \mathrm{~m}^{-2} \mathrm{~K}^{-1}\right]$ \\
\hline Contact of cylinder head vs. cylinder head gasket & 1 & 6000 \\
\hline Contact of cylinder head vs. inlet valve seat & $2 \mathrm{a}, \mathrm{b}, \mathrm{c}$ & 6000 \\
\hline Contact of cylinder head vs. exhaust valve seat & $3 \mathrm{a}, \mathrm{b}, \mathrm{c}$ & 6000 \\
\hline Contact of inlet valve vs. seat & 4 & 6000 \\
\hline Contact of inlet valve vs. valve guide & 5 & 600 \\
\hline Contact of exhaust valve vs. seat & 6 & 6000 \\
\hline Contact of exhaust valve vs. valve guide & 7 & 600 \\
\hline Contact of inlet valve guide vs. cylinder head & 8 & 6000 \\
\hline Contact of exhaust valve guide vs. cylinder head & 9 & 6000 \\
\hline Contact of cylinder head vs. fuel injector (O-ring) & 10 & 6000 \\
\hline Contact of cylinder head vs. fuel injector & 11 & 6000 \\
\hline
\end{tabular}

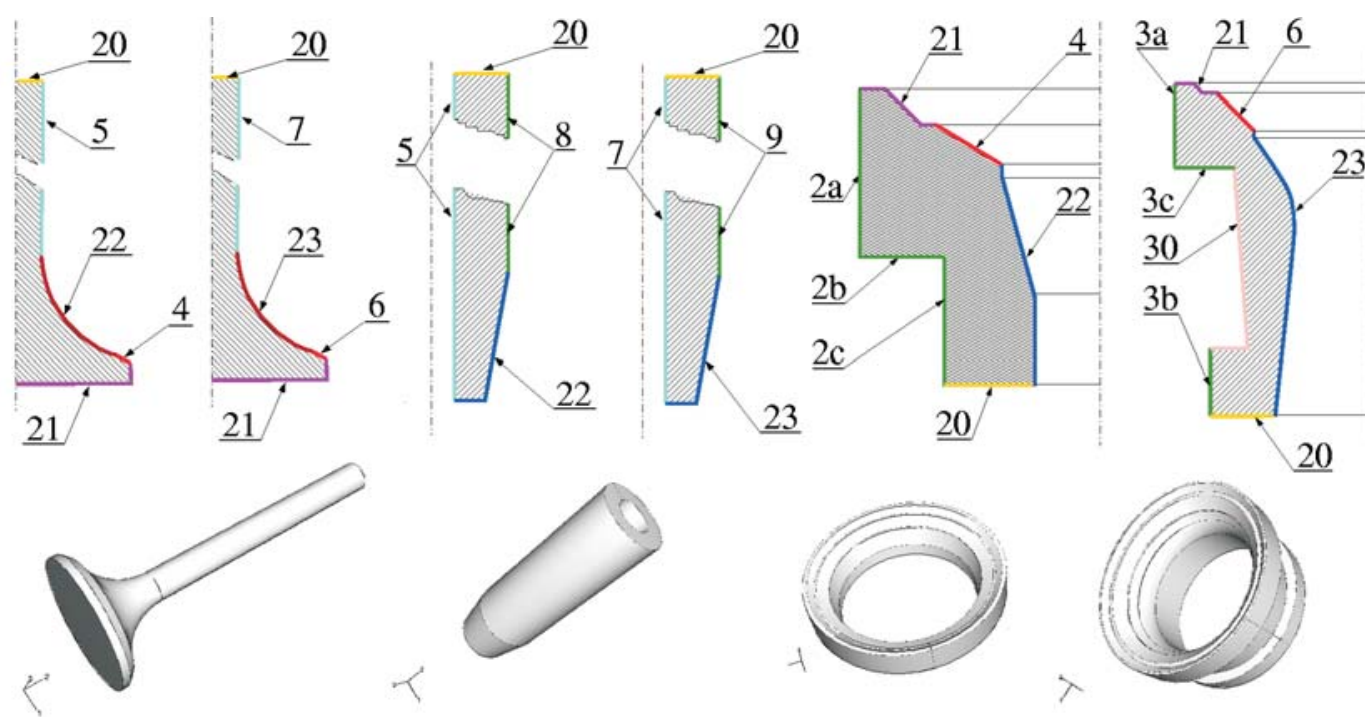

Fig. 4: Interactions and boundary conditions on other parts of the cylinder-head assembly 
Table 3: Boundary conditions considered in FE model (acting surfaces linked in Fig. 3 and 4)

\begin{tabular}{|c|c|c|c|}
\hline Boundary condition description & Link & Heat transfer coefficient $\left[\mathrm{W} \mathrm{m}^{-2} \mathrm{~K}^{-1}\right]$ & Bulk temperature $[\mathrm{K}]$ \\
\hline $\begin{array}{l}\text { Insulated surfaces } \\
\text { (negligible heat-transfer rate) }\end{array}$ & 20 & $\begin{array}{c}0 \\
\text { (adiabatic) }\end{array}$ & - \\
\hline Free surfaces (contact with ambient air) & 29 & 5 & 320 \\
\hline Cooling passages & 30 & $3000 *$ & 350 \\
\hline In-cylinder surfaces & 21 & 450 & 1120 \\
\hline Intake-port surfaces & 22 & 800 & 330 \\
\hline Exhaust-port surfaces & 23 & 800 & 700 \\
\hline
\end{tabular}

*For cases B and C, the heat-transfer coefficient was assumed dependent on surface temperature

tailed thermodynamic analysis of the engine operating cycle performed with the use of the 0-D thermodynamic model OBEH, see [1]. This analysis uses the well-known Eichelberg empirical heat-transfer coefficient correlation.

The remaining boundary conditions on outside surfaces most exposed to the ambient air temperature are described using estimated values of the heat transfer coefficient; in special cases the heat-transfer is neglected. More detailed information on the used values are provided in Table 3 in conjunction with Fig. 3 and 4.

The coolant-side boundary conditions for the water-cooled passages are based on values reported in the literature, see [4]. However, if local boiling occurs at the surface, different relationships for $h$ must be used. Heat-transfer coefficients for boiling features even more complicated dependencies, since in addition to all the mentioned influences affecting the values of heat-transfer in convection, in boiling processes additional variables play a role, e.g., those linked to the phase change, microstructure and material of the surface. In the first computed case (A) the possibility of occurrence of local boiling effects was neglected. However, the computed results suggest that the boiling point of water was exceeded in some parts of the cooling passages. In further computations (B, C) the temperature-dependent heat-transfer coefficient was assumed, see Fig. 5, the values of which approximately follow, the steep dependence of the heat-transfer coefficient on the temperature of superheating, as reported in $[4,5]$. The reasons for this simple approximation were twofold: the com-

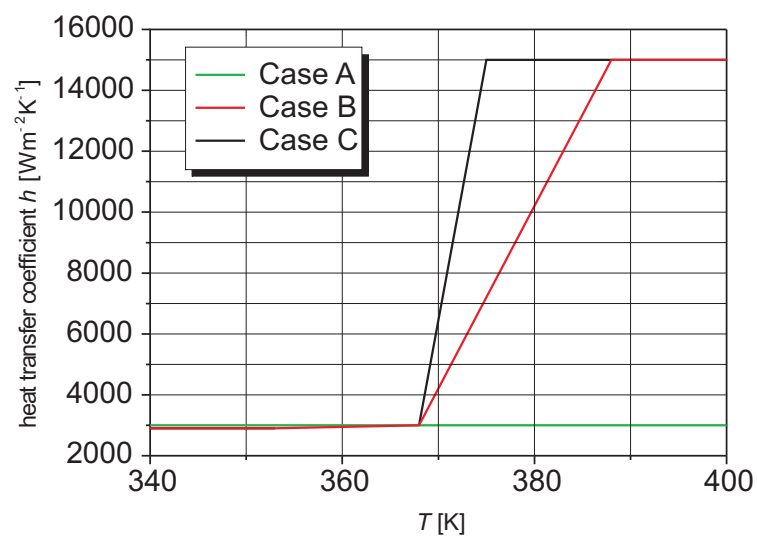

Fig. 5: Dependency of the heat-transfer coefficient in the cooling passages on surface temperature for cases $\mathrm{A}, \mathrm{B}$, and $\mathrm{C}$ plexity of the problem, resulting in significant deviations of the coefficient values calculated according to the different equations, and the multiplicity of variables needed, some of which were not at our disposal. In this connection, two different dependencies $h=h(T)$ were assumed in cases B and C, which made it possible to assess the sensitivity of the computational results to the potential errors in approximation of the heat-transfer coefficient for boiling.

\section{Results and discussions}

Experimental data provided by the engine manufacturer enabled us to make a comparison with the computed results. The temperature measurement arrangement with the positioning of all the measured points is sketched in Fig. 6. The thermocouples were placed in special bores. All the bores were situated at a distance of $18 \mathrm{~mm}$ from the bottom margin of the cylinder head. Despite the lack of further detailed information on conditions of the experiment (errors caused

Table 4: Comparison of computed with measured temperatures points $\mathrm{P} 1-\mathrm{P} 13$

\begin{tabular}{|c|c|c|c|c|}
\hline \multirow{2}{*}{$\begin{array}{c}\text { Measured } \\
\text { point }\end{array}$} & \multicolumn{4}{|c|}{ Temperature [K] } \\
\cline { 2 - 5 } & Case A & Case B & Case C & Experimental data \\
\hline 1 & 568 & 488 & 488 & 425 \\
\hline 2 & 558 & 485 & 485 & 509 \\
\hline 3 & 497 & 430 & 429 & 442 \\
\hline 4 & 517 & 453 & 453 & - \\
\hline 5 & 493 & 434 & 433 & 412 \\
\hline 6 & 528 & 454 & 453 & 448 \\
\hline 7 & 508 & 444 & 443 & 415 \\
\hline 8 & 553 & 501 & 501 & 468 \\
\hline 9 & 501 & 443 & 443 & 394 \\
\hline 10 & 553 & 501 & 501 & 430 \\
\hline 11 & 516 & 448 & 448 & 400 \\
\hline 12 & 489 & 445 & 443 & 361 \\
\hline 13 & 518 & 486 & 483 & 414 \\
\hline & & & & \\
\hline
\end{tabular}


by the measuring equipment, influence of the location and fixation of the thermocouples in the bores, etc.), the authors found the data provided a useable and useful resource for verification of the presented model.

Direct comparison is disabled by the fact that the experimental data and the computed values do not correspond exacly to the same load of the engine. Thermal boundary conditions for the FE analysis were computed for about $5 \%$ higher BMEP (break mean effective pressure) than that

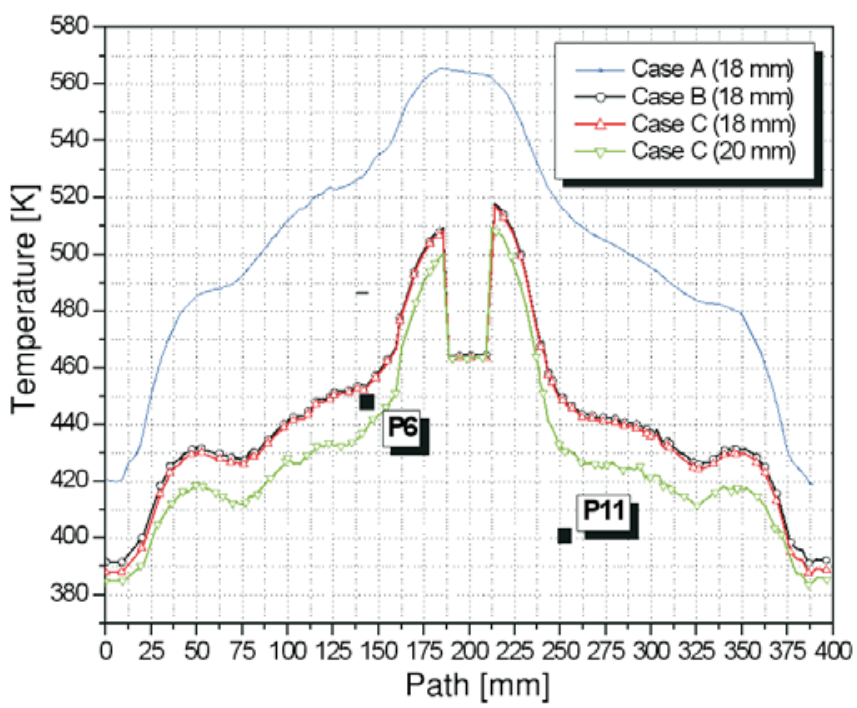

Fig. 6: Computed temperature vs. path distance. Paths go through measured points P6, P11 defined in Fig. 7. Squares indicate measured temperature. prevailing during the experiment. Accordingly to [2], the experimental temperatures for the same BMEP as those used in FE analysis might cause an increase in observed temperatures of about $15 \mathrm{~K}$. Table 4 provides a comparison of the results of all the computed cases $(\mathrm{A}, \mathrm{B}, \mathrm{C})$ with those from measurement. The tabulated values indicate significantly closer agreement of results of cases B, C with experimental data, which confirms the importance of including the local boiling effects. The negligible differences of values computed for cases $\mathrm{B}$ and $\mathrm{C}$ indicate the insensitivity of the steady-state temperature field to any possible shortcoming in the evaluation of the heat-transfer coefficient for boiling, see Fig. 5, which confirms the suitability of the approach chosen for incorporating of the local boiling effects into the FE model.

Due to some uncertainty about the precision of the placement of quite lengthy bores, the sensitivity of the calculated values to the positioning of the measuring points was tested. Therefore, for case $\mathrm{C}$, all the temperatures were observed at a distance of $20 \mathrm{~mm}$ from the bottom margin of the cylinder head. The comparison displayed in Fig. 6 affords a rough estimation of the possible errors arising from the inaccurate fit of the points at which the temperatures were observed in the model to the real measuring points.

The results of the calculations shown in the cross-section in Fig. 8 provide some interesting information on the temperature distribution within the valves and seats. Especially, there is apparently a positive influence of cooled seats of exhaust valves on the thermal loading of those parts, as the temperature values within the exhaust valves just slightly exceed those in the intake valves (experiencing significantly lower thermal loading).

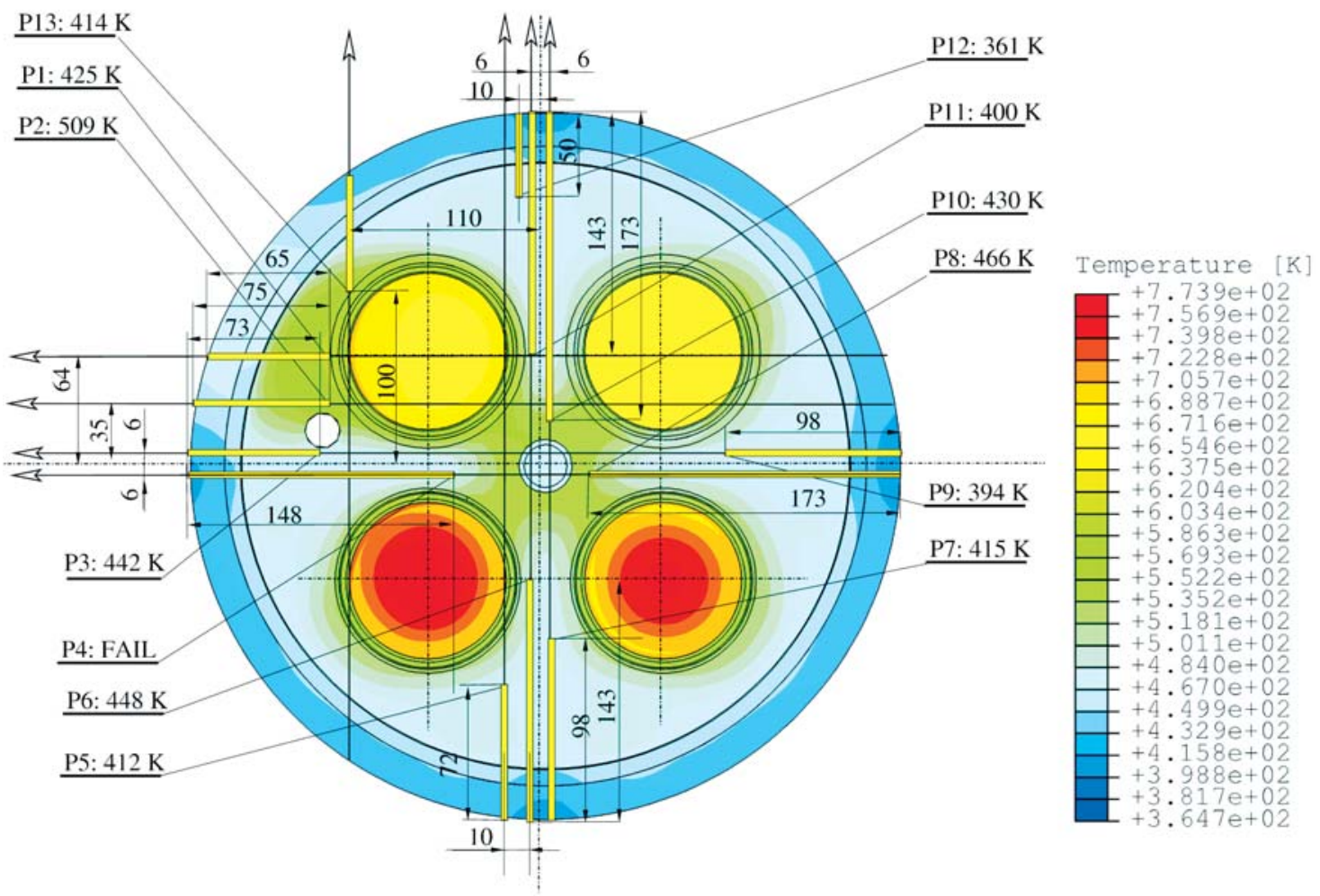

Fig. 7: Measured points P1-P13 distribution over the head. All measurement holes are positioned $18 \mathrm{~mm}$ from the bottom of the head. Colored isotherms represent the computational results of case C. (measured values linked directly with points) 

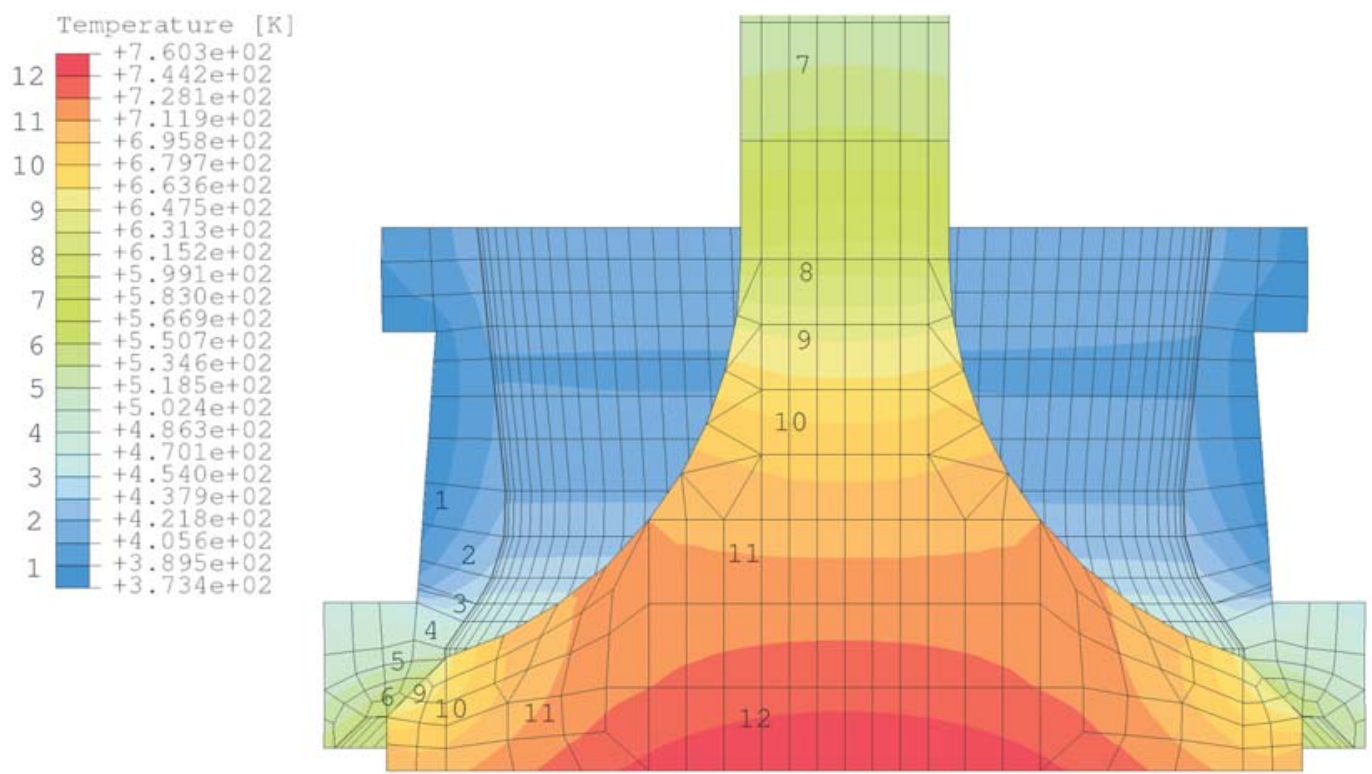

Fig. 8: Temperature field on exhaust valve and seat (case C)

\section{Conclusion}

A steady state heat transfer analysis of a C 28 big diesel engine cylinder head assembly was peformed using FEM. The model was verified using measured temperatures. The computed values correspond to the experimental data. The results of computation confirmed the need to incorporate the possible occurrence of local boiling and associated steep changes in the values of the heat-transfer fluxes. Thermal loading of the head assembly will be performed in the near future.

\section{References}

[1] Macek, J., Vávra, J., Tichánek, R., Diviš, M.: Výpočet oběhu motoru 6c28 a stanoveni okrajouých podminek pro pernostní a deformačni výpočet dna hlavy válce. (in Czech) ČVUT v Praze, Fakulta strojní, VCJB, 2001.

[2] Macek, J., Vítek, O., Vávra, J.: Kogeneračni jednotka s plynovým motorem o výkonu větš́m než $3 M W-I I$. (in Czech) ČVUT v Praze, Fakulta strojní, 2000.

[3] Horák, F., Macek, J.: Use of Predicted Fields in Main Parts of Supercharged Diesel Engine. Proceedings of XIX. Conference of International Centre of Mass and Heat Transfer. New York: Pergamon Press, 1987.

[4] Kreith, F., Black, W.: Basic Heat Transfer. New York: Harper and Row, 1980.
[5] Baehr, H. D., Stephan, K.: Heat and Mass Transfer. Berlin: Springer-Verlag, 1998.

Ing. Marcel Diviš

phone: +420224351827

e-mail: divis@student.fsid.cvut.cz

Ing. Radek Tichánek

phone: +420224352507

e-mail: tichanek@student.fsid.cvut.cz

Department of Automotive and Aerospace Engineering

Czech Technical University in Prague

Josef Božek Research Center

Technická 4

16607 Prague 6, Czech Republic

Ing. Miroslav Španiel, CSc.

phone: +420224352561

e-mail: spaniel@lin.fsid.cvut.cz

Department of Mechanics

Czech Technical University in Prague

Josef Božek Research Center

Technická 4

16607 Prague 6, Czech Republic 